\title{
MARX E ENGELS: A RELAÇÃO INTELECTUAL REVISITADA A PARTIR DE UMA PERSPECTIVA ECOLÓGICA*
}

\author{
MARX E ENGELS: LA RELACIÓN INTELECTUAL REVISADA DESDE UNA \\ PERSPECTIVA ECOLÓGICA
}

\section{MARX AND ENGELS: THE INTELLECTUAL RELATIONSHIP REVISITED FROM AN ECOLOGICAL PERSPECTIVE}

DOI: http://doi.org/10.9771/gmed.v13i2.45509

\section{Kohei Saito ${ }^{1}$}

Resumo: O Marxismo Ocidental assume frequentemente a divisão intelectual do trabalho entre Marx e Engels. Conforme tal perspectiva, este último especializou-se no campo da "natureza", enquanto o primeiro analisou particularmente a "sociedade" humana. No entanto, este binário natureza-sociedade não se sustenta mais: novos materiais publicados recentemente pelo projeto Marx-Engels-Gesamtausgabe (Mega) mostram que Marx também estudou de modo intenso as ciências naturais, principalmente em seus últimos anos de vida. Porém, houve uma tentativa de Engels em subestimar a importância da pesquisa científica natural de Marx. Estimulado pelas expressivas discussões sobre a ecologia de Marx entre os ecossocialistas, este artigo visa explicitar o escopo teórico da crítica ecológica de Marx ao capitalismo com base no projeto Mega. Em contraste com John Bellamy Foster e Paul Burkett, que não reconhecem nenhuma diferença significativa entre Marx e Engels no que diz respeito à ecologia, argumentamos que através da Mega é possível identificar elementos únicos da ecologia de Marx que são distintas daquelas apresentadas por Engels em aspectos centrais. A crítica ecológica de Engels, desenvolvida principalmente em $A$ ideologia alemã e no Manifesto comunista, durante a década de 1840, permaneceu dentro do esquema do "antagonismo entre a cidade e o campo", e esta perspectiva foi mantida em Dialética da natureza e no Anti-Dühring na década de 1870. Por outro lado, Marx, depois de ler a sétima edição de Agricultural Chemistry de Justus von Liebig em 1865/66, desenvolveu sua teoria da "ruptura metabólica", que vai para além da ideia bastante estática do "antagonismo entre a cidade e o campo". Após 1868, Marx estudou ainda mais entusiasticamente várias disciplinas das ciências naturais, como química, geologia e botânica, a fim de examinar a (in)sustentabilidade do modo de produção capitalista, cujo desejo ilimitado de valorização do capital acentua de forma inevitável graves desequilíbrios em várias esferas do planeta. Particularmente, os cadernos de excertos sobre as obras de Carl Fraas e Joseph Beete Juke documentam que os interesses ecológicos de Marx estiveram sempre expansão até o último momento de sua vida. Marx não foi capaz de integrar seus novos conhecimentos de ciências naturais, mas hoje o projeto Mega finalmente lança mais luz sobre esses aspectos ecológicos desconhecidos da crítica de Marx à economia política.

Palavras-chave: Marx-Engels-Gesamtausgabe (Mega). Metabolismo. Crise ecológica. Dialética da natureza. Marxismo Ocidental.

Resumen: El Marxismo Occidental a menudo asume la división intelectual del trabajo entre Marx y Engels. De acuerdo con esta perspectiva, este último se especializó en el campo de la "naturaleza", mientras que el primero

Germinal: marxismo e educação em debate, Salvador, v.13, n.2, p.20-38, ago. 2021. ISSN: 2175-5604 
analizó particularmente la "sociedad" humana. Sin embargo, este binario naturaleza-sociedad ya no se sostiene: los nuevos materiales publicados recientemente por el proyecto Marx-Engels-Gesamtausgabe (Mega) muestran que Marx también estudió intensamente las ciencias naturales, especialmente en sus últimos años de vida. Sin embargo, Engels intentó subestimar la importancia de la investigación científica natural de Marx. Estimulado por las discusiones expresivas sobre la ecología de Marx entre ecosocialistas, este artículo tiene como objetivo aclarar el alcance teórico de la crítica ecológica de Marx al capitalismo basada en el proyecto Mega. En contraste con John Bellamy Foster y Paul Burkett, quienes no reconocen ninguna diferencia significativa entre Marx y Engels con respecto a la ecología, sostenemos que a través de Mega es posible identificar elementos únicos de la ecología de Marx que son distintos de los presentados por Engels en aspectos centrales. La crítica ecológica de Engels, desarrollada principalmente en La ideología alemana y el Manifiesto comunista, durante la década de 1840, se mantuvo en el marco del "antagonismo entre ciudad y campo", y esta perspectiva permanece en Dialéctica de la naturaleza y en Anti-Dühring en el 1870. Por otro lado, Marx, después de leer la séptima edición de Agricultural chemistry de Justus von Liebig en 1865/66, desarrolló su teoría de la "rotura metabólica", que va más allá de la idea bastante estática de "antagonismo entre ciudad y campo". Después de 1868, Marx estudió con aún más entusiasmo diversas disciplinas de las ciencias naturales, como la química, la geología y la botánica, con el fin de examinar la (in)sostenibilidad del modo de producción capitalista, cuyo deseo ilimitado de apreciación del capital acentúa inevitablemente graves desequilibrios en varias esferas del planeta. En particular, los cuadernos de extractos de las obras de Carl Fraas y Joseph Beete Juke documentan que los intereses ecológicos de Marx siempre se expandieron hasta el último momento de su vida. Marx no pudo integrar su nuevo conocimiento de las ciencias naturales, pero hoy el Mega finalmente arroja más luz sobre estos aspectos ecológicos desconocidos de la crítica de Marx a la economía política.

Palavras-clave: Marx-Engels-Gesamtausgabe (Mega). Metabolismo. Crisis ecológica. Dialéctica de la naturaliza. Marxismo Occidental.

Abstract. Western Marxism often assumes the intellectual division of labor between Marx and Engels, according to which the latter specialized the sphere of "nature," while the former mainly analyzed human "society." However, this nature-society-binary does not hold any more: recent publication of new materials in the Marx-EngelsGesamtausgabe (Mega) shows that Marx also intensively studied natural sciences especially in his late years, but Engels attempted to undertone the importance of Marx's natural scientific research. Stimulated by robust discussions on Marx's ecology among eco-socialists, this paper aims to clarify the theoretical scope of Marx's ecological critique of capitalism based the Mega. In contrast to John Bellamy Foster and Paul Burkett, who do not see any significant difference between Marx and Engels with regard to ecology, I argue that the MEGA makes it possible to see unique aspects of Marx's ecology that is different from Engels' in some key aspects. Engels' ecological critique remained within the scheme of the "antagonism between town and country" developed mainly in The german ideology and The communist manifesto during the 1840's even after he started preparing his Dialectics of nature and Anti-Dübring in the 1870's. In contrast, Marx, after reading the $7^{\text {th }}$ edition of Justus von Liebig's Agricultural chemistry in 1865/66, developed his theory of "metabolic rift," which goes beyond a rather static idea of the "antagonism between town and country." After 1868 Marx even more passionately studied various disciplines of natural science such as chemistry, geology and botanic in order to examine the (un)sustainability of the capitalist mode of production whose boundless desire for capital valorization inevitably deepens severe disharmonies in various spheres of the earth. Especially, Marx's excerpt notebooks on works by Carl Fraas and Joseph Beete Juke document that his ecological interests never ceased to expand until the last moment of his life. Marx was not able to integrate his new natural scientific insights, but today the Mega finally sheds more lights to these unknown ecological aspects of Marx's critique of political economy.

Keywords: Marx-Engels-Gesamtausgabe (Mega). Metabolism. Ecological crisis. Dialectics of nature. Western Marxism. 


\section{Introdução}

Têm sido suficientemente notórias as inúmeras críticas contra Marx devido ao seu suposto "prometeísmo", e até mesmo muitos autodeclarados marxistas concluíram que seu produtivismo é incompatível com o ambientalismo. Entretanto, com a intensificação das crises ecológicas sob a vigência da globalização neoliberal, a "ecologia de Marx" recebe atualmente maior atenção. Ecossocialistas empregam o conceito de "ruptura metabólica" originado de $O$ capital e analisam ativamente o lado destrutivo da produção capitalista como o aquecimento global, desequilíbrio do ciclo de nitrogênio e a extinção de espécies. Consequentemente, a ecologia torna-se um dos campos centrais para o enriquecimento do legado de $O$ capital de Marx após 150 anos.

Todavia, nem todo marxista concorda com a ecologia de Marx. Persistem respostas para rejeitá-la, uma vez que suas considerações esporádicas em $O$ capital não podem oferecer uma base teórica para analisar as crises ecológicas atuais. Especialmente, "marxistas ocidentais" muitas vezes refutam um projeto ecossocialista. Por exemplo, em uma entrevista publicada na revista Examined life, Slavoj Žižek afirma que a ecologia é "um novo ópio para as massas” (ŽIŽEK, 2009, p.158).

Uma das razões para tal desprezo pode estar relacionada a um antigo problema que envolve a “relação intelectual” entre Marx e Engels. O Marxismo Ocidental iniciado por Georg Lukács considerou as ciências naturais como área de especialidade de Engels. Contudo, uma vez que o Marxismo Ocidental negligenciou a pesquisa de Marx sobre ciências naturais, ele enfrenta o dilema de não poder desenvolver uma crítica marxista da ecologia, a menos que admita a sua interpretação unilateral. Devido a esse dilema, alguns marxistas rejeitam histericamente a ideia do ecossocialismo.

Por outro lado, John Bellamy Foster e Paul Burkett adotaram uma abordagem mais fecunda. Argumentando que não existe diferença da perspectiva entre Marx e Engels em termos de ecologia, eles desenvolveram o conceito de ruptura metabólica (FOSTER e BURKETT, 2016, p.16). Ambos efetivamente empregam a estrutura metodológica de Marx, analisam as questões ambientais atuais e demonstram a relevância da ecologia marxiana para o momento presente (ver FOSTER et al., 2011). Também mostram a importância da ecologia de Marx como parte integrante de seu projeto geral de crítica da economia política e continuam dialogando com a economia ecológica (ver BURKETT, 2006). No entanto, daí coloca-se também a questão de saber se as diferenças entre Marx e Engels em termos de economia política, cuja existência Foster e Burkett não negam, resultam em visões distintas sobre a ecologia.

Este artigo apresenta uma abordagem sintética: ao focar a pesquisa de Marx no campo das ciências naturais ignorada pelo marxismo ocidental, pretende revelar diferenças ecológicas entre Marx e Engels. Pressupondo, em certa medida, colaborações e interpretações comuns entre eles, analiso $O$ capital e sua relação com os novos materiais publicados através do Marx-Engels-Gesamtausgabe (Mega), que não foi 
considerado por Foster e Burkett. Com isso, será possível traçar a direção teórica para desenvolver o projeto incompleto de $O$ capital de Marx no século 21.

\section{Divisão intelectual do trabalho?}

O Marxismo Ocidental considerou as ciências naturais como área de especialidade de Engels e a apartaram da filosofia de Marx com a finalidade de resgatá-la do determinismo mecanicista e econômico do "materialismo dialético" soviético. Na verdade, se Georg Plekhanov estivesse certo no que tange a existência independente da dialética da natureza, seria possível conceituar um método dialético por meio das ciências naturais e deste modo aplicá-lo à sociedade humana. O Marxismo Ocidental problematizou assim o efeito positivista e tentou resgatar Marx de uma cosmovisão de mundo mecanicista limitando de forma restrita a dialética à sociedade. O Marxismo Ocidental, ao enfatizar a divisão do trabalho intelectual entre Marx e Engels, colocou o último como bode expiatório, que seria o responsável por estender a dialética para a natureza (LUKÁCS, 1971, p.24). Ironicamente, foi o próprio Engels que enfatizou a divisão do trabalho. Conforme seu prefácio na segunda edição do Anti-Dühring publicado após a morte de Marx: "Marx foi um consumado matemático: mas, de nossa parte, não pudemos estudar senão fragmentariamente, intermitentemente e esporadicamente as ciências naturais". No entanto, Engels mais tarde, refletindo sobre este ponto cego, pontua: "fiz uma completa mise en mue, como diria Liebig, das matemáticas e ciências naturais" (ENGELS, 1987a, p. 11).

De fato, Anti-Dübring e Dialética da natureza registram que Engels estudou física, química e biologia com muita seriedade. Suas obras influenciaram profundamente a formação de uma cosmovisão do marxismo tradicional porque Marx não escreveu um livro sobre a natureza. Porém, Engels em seu prefácio ao Anti-Dübring omitiu uma informação importante dos leitores: naquele momento, como editor de $O$ capital estava ocupado com a organização dos manuscrtios e anotações de Marx, ele sabia portanto que Marx também estudava avidamente as ciências naturais. Todavia, Engels não meciona este fato, e simplesmente diz que Marx apenas de forma "fragmentada, intermitente e esporádica acompanhou as ciências naturais."

Marx, em sua carta a Engels datada em 4 de julho de 1864, explicita que ele foi motivado por Engels para ler Ficologia de Carperter assim como Anatomia do cérebro e do sistema nervoso de Spurzheim, e escreveu: "Eu sigo seus passos invariavelmente" (MARX e ENGELS, 1985, p.546). Entretanto, ao ler a sétima edição da Química agrícola de Justus von Liebig em 1865, Marx intensifica sua leitura sobre ciências naturais. Sua lista de leituras após 1868 abrange várias áreas como química, geologia, mineralogia, fisiologia e botânica. Em 19 de dezembro de 1882 Engels até reconheceu que Marx estava mais familiarizado com o que pode ser considerado o problema do aumento da entropia com o consumo de combustível fóssil: o "trabalhador individual não é simplesmente um estabilizador do calor solar do presente, mas também um esbanjador do calor do solar do passado. Quanto às reservas de energia, carvão, minerais, florestas etc., que

Germinal: marxismo e educação em debate, Salvador, v.13, n.2, p.20-38, ago. 2021. ISSN: 2175-5604 
temos desperdiçado, você está mais bem informado do que eü" (MARX e ENGELS, 1992, p.411, grifo nosso). No entanto, Engels, no prefácio do Anti-Dühring, não mencionou este ponto e, em vez disso, declarou que sua dialética da natureza era uma aplicação do método dialético "fundado e desenvolvido" por Marx (ENGELS, 1987a, p.9).

Isso é estranho. Engels enfatizou que as ideias desenvolvidas no Anti-Dübring são totalmente compatíveis com a visão de Marx, dizendo que "leu todo o manuscrito para ele antes de ser impresso", e Marx concordou integralmente com o livro (ENGELS, 1987a, p.9). No entanto, tal "prova" foi destacada somente após a morte de Marx (CARVER, 1983, p.123). Por outro lado, Engels não se referiu ao envolvimento sério de Marx com as ciências naturais, embora a existência das anotações de Marx sobre as ciências naturais fosse a prova mais contundente de que a dialética da natureza era um projeto colaborativo deles. Assim, ficamos tentados a interpretar sintomaticamente esse silêncio incomum: Engels admitiu tacitamente que o interesse de Marx pelas ciências naturais possuía um caráter diferente do seu.

\section{O escopo da teoria da ruptura metabólica}

Hoje, como é de amplo conhecimento que tanto Marx quanto Engels estudaram apaixonadamente a ciência natural, a unilateralidade do Marxismo Ocidental fica patente. No entanto, não se pode argumentar imediatamente que eles compartilhavam o mesmo interesse pela ecologia. É necessário investigar esta questão com mais cuidado.

Obviamente, nem todos os marxistas ocidentais merecem o mesmo grau de crítica. Embora Lukács a princípio tenha reprovado a aplicação da dialética à natureza, posteriormente ele mudou sua visão, admitindo que Marx não separou completamente a relação entre "sociedade" e "natureza", mas compreendeu ambas em sua integridade. Lukács reconheceu que o conceito de "metabolismo [Stoffwechsel]" expressa essa unidade, que se tornou o termo chave para a análise marxista de "ruptura metabólica" (ver FOSTER, 2013).

O significado mais importante do conceito de metabolismo de Marx em $O$ capital é sua caracterização do trabalho como a atividade mediadora do metabolismo entre os humanos e a natureza: "Trabalho é, antes de tudo, um processo entre o homem e a natureza, um processo pelo qual o homem, por meio de suas próprias ações, medeia, regula e controla o metabolismo entre ele e a natureza" (MARX, 1976, p.283). Em qualquer sociedade, os humanos devem trabalhar a natureza de maneira consciente e teleológica e satisfazer as necessidades para viver neste planeta.

Marx expressou essa relacionalidade transistórica entre os humanos e a natureza com o conceito de "metabolismo". As formas concretas do metabolismo entre os humanos e a natureza, entretanto, diferem amplamente, dependendo de como essa atividade mediadora do trabalho está socialmente organizada. Nos Grundrisse, Marx apontou a relação singular entre os humanos e a natureza sob a produção capitalista caracterizada pela "separação" dos seres humanos da natureza (MARX, 1973, p.489). O

Germinal: marxismo e educação em debate, Salvador, v.13, n.2, p.20-38, ago. 2021. ISSN: 2175-5604 
capital de Marx analisa precisamente a alienação humana e a alienação da natureza sob a produção capitalista devido esta relação alienada.

Conforme elucidado no volume 1 de $O$ capital, o "processo de trabalho" transistórico recebe uma nova forma como um "processo de valorização" sob o capitalismo, e o processo material do metabolismo entre os humanos e a natureza é consequentemente transformado. Enquanto as sociedades pré-capitalistas visavam à produção de valores de uso concretos, a produção capitalista busca principalmente a produção de valor. Enquanto o trabalho costumava ser conduzido sob limitações sociais e naturais para satisfazer as necessidades humanas concretas, a produção capitalista busca a valorização infinita, de modo que o trabalho e a natureza sejam completamente reorganizados a partir de uma perspectiva da objetificação máxima do trabalho abstrato.

Sob a primazia da lógica de valorização do capital, não só o funcionamento da natureza, mas também o aspecto do trabalho concreto no processo de trabalho é abstraído e subordinado. O metabolismo entre os humanos e a natureza é mediado pelo valor como a objetificação do trabalho abstrato, que nada mais é do que o dispêndio da força de trabalho humana em geral, e é transformado da maneira mais favorável à valorização do capital. O capital de Marx salienta reiteradamente para o caráter de roubo dessa transformação do mundo material da perspectiva da produção de mais-valor e para o perigo de consequências destrutivas: "A mesma rapacidade cega que, num caso, exauriu o solo, no outro matou na raiz a força vital da nação" (MARX, 1976, p.348). Marx problematizou a dilapidação capitalista em relação a dois fatores fundamentais de produção: o esgotamento da "força de trabalho" e das "forças naturais".

É notório que foi a obra Química agrícola de Liebig que levou Marx a apresentar uma análise do "sistema de roubo" na agricultura em O capital (ver FOSTER, 2000, p.155). Liebig criticou a agricultura moderna como um roubo, que visa apenas a maximização do lucro a curto prazo e permite que as plantas absorvam o máximo possível de nutrientes do solo sem reposição. Ele ainda advertiu contra a decadência da civilização europeia devido a perda da base material em decorrência do esgotamento do solo. Marx em O capital teceu elogios aos "méritos imortais" de Liebig por revelar "o aspecto negativo e destrutivo da agricultura moderna" e escreveu:

[A produção capitalista] impede o retorno ao solo daqueles elementos que lhe são constitutivos e foram consumidos pelo homem sob forma de alimentos e vestimentas, retorno que é a eterna condição natural da fertilidade permanente do solo. Com isso, ela destrói tanto a saúde física dos trabalhadores urbanos como a vida espiritual dos trabalhadores rurais. (MARX, 1976, p.637).

Durante o século XIX o esgotamento do solo tornou-se uma questão social. Alimentos consumidos pelo aumento populacional nas grandes cidades eram lançados através dos vasos sanitários para os rios como esgotos. Os excrementos exalavam um mau cheiro na cidade de Londres e o cólera tornou-se predominante. Aqui, o antagonismo entre a agricultura e a indústria é manifesto. Marx, 
fundamentado na Química agrícola de Liebig, formulou o problema da exaustão do solo como uma contradição que a produção capitalista criou em meio ao metabolismo entre os humanos e a natureza.

Marx tinha profundo apreço por Liebig porque a obra Química agrícola forneceu uma base científica para sua análise crítica da divisão do trabalho, que ele já havia conceituado como a "contradição entre a cidade e o campo" em $A$ ideologia alemã (ENGELS 1987, p.64). Após acolher o pensamento de Liebig, Marx reconheceu nitidamente a necessidade de refletir de maneira mais detalhada como o capitalismo transforma e enfraquece a relação entre os humanos e a natureza. Em outras palavras, uma razão para sua pesquisa intensiva em ciências naturais é investigar as causas e influências de uma "ruptura irreparável" no metabolismo universal da natureza, como no volume 3 de O capital (MARX, 1981, p.949).

Historicamente falando, o problema da exaustão do solo devido à falta de substâncias inorgânicas foi em grande parte resolvido graças à invenção do processo Harber-Bosch, permitindo a produção industrial em massa de amônia. No entanto, a excessiva dependência de fertilizantes químicos gera outros problemas, como baixa capacidade de retenção de água e nutrientes e maior vulnerabilidade a doenças e insetos. O nitrogênio remanescente no solo também flui para o meio ambiente, causando marés vermelhas, enquanto o nitrato de nitrogênio polui água e vegetais. Nesse sentido, "rupturas" do metabolismo não são resolvidas, mas, na melhor das hipóteses, "deslocadas" para outros problemas (ver CLARK; YORK, 2008). "Mudanças metabólicas" semelhantes podem ser encontradas nas indústrias extrativas de mineração de petróleo e metais raros. $\mathrm{Na}$ medida em que o valor não pode levar totalmente em conta o metabolismo entre os humanos e a natureza, a realização da produção sustentável sob o capitalismo sempre enfrenta barreiras intransponíveis. Assim, a unificação da teoria do valor de Marx e metabolismo em $O$ capital fornece uma base metodológica para analisar criticamente o sistema de roubo do capitalismo.

\section{Engels e $\boldsymbol{O}$ capital}

Apesar de empreender um esforço muito sério para estudar ciências naturais, Marx faleceu antes de concluir $O$ capital, portanto coube a Engels a tarefa de editar os volumes 2 e 3 de $O$ capital. Na ocasião da escrita do Anti-Dübring, quando Engels negligenciou os cadernos de notas de Marx sobre ciências naturais, existia uma diferença sutil entre Marx e Engels sobre o conceito de "metabolismo". Este problema é perceptível na edição de Engels de $O$ capital.

Certamente, Engels reconheceu a importância da crítica de Liebig à agricultura de roubo. Por exemplo, em Sobre a questão da moradia, ele se referiu a Liebig e apontou a "antítese da cidade e do campo" e defendeu a reconstrução de "uma relação intrínseca entre a produção industrial e agrícola", bem como reivindicou a "combinação da agricultura com as indústrias manufatureiras" no Manifesto do Partido Comunista (ENGELS, 1988, p.384; MARX E ENGELS, 1976, p.505). Também na edição do volume 3 de O capital, Engels complementou a descrição de Marx da agricultura de roubo através de casos concretos. Ele acrescentou a seguinte passagem, para citar um trecho: "Em Londres, por exemplo, eles não podem 
fazer nada melhor com o excremento produzido por 4,5 milhões de pessoas do que poluir o Tamisa com ele, a um custo monstruoso" (MARX, 1981, p.195). Aqui se pode observar a colaboração intelectual entre Marx e Engels.

No entanto, as coisas parecem diferentes quando o "metabolismo" está em discussão. Embora Engels estivesse ciente de que Marx discutiu o problema da exaustão do solo com o conceito de metabolismo de Liebig, ele alterou intencionalmente uma frase em particular no volume 3 de $O$ capital. Em seu manuscrito original, Marx escreveu:

Deste modo, a grande propriedade do solo produz condições para o surgimento de uma ruptura irremediável no processo interdependente entre o metabolismo social e o metabolismo natural, prescrito pelas leis naturais do solo; disto resulta a dilapidação da vitalidade do solo, e o comércio carrega tal devastação muito além das fronteiras do próprio país (Liebig). (MARX, 1992, p.752-3)2

Referindo-se a Liebig, Marx destacou o perigo de uma grave ruptura global no processo interdependente entre "metabolismo social" (produção, circulação e consumo capitalista) e "metabolismo natural". Ele enunciou claramente uma relação conflituosa entre a determinação da forma econômica capitalista e as propriedades naturais no mundo material.

Engels modificou a primeira frase da seguinte maneira: "desta forma, produz condições que geram uma ruptura irreparável no processo interdependente do metabolismo social, um metabolismo prescrito pelas leis naturais da própria vida" (MARX, 1981, p.949). Agora a palavra "metabolismo natural" é omitida e "solo" é alterado para "vida", de modo que o contraste entre o metabolismo social e natural se torna obscuro. Certamente, há vários casos em que Engels modificou as expressões de Marx quando não eram muito claras, confusas ou equivocadas. No entanto, nesta passagem, a intenção de Marx não é apenas clara, mas também esta é uma passagem chave para sua teoria do metabolismo. O que a mudança de Engels implica?

Aqui é importante considerar a "dialética da natureza" de Engels. Segundo ele, o Anti-Dübring pretendia apreender as leis que penetram na natureza e na história e, especialmente, "despojá-las desta forma mística [hegelina] e manifestá-las em sua mais completa simplicidade e universalidade". Seu projeto afirmava ser um projeto materialista, o que evitou o equívoco de Hegel de "impor à natureza leis dialéticas predeterminadas", mas se propunha a "descobri-las e desenvolvê-las, partindo da mesma natureza". (ENGELS, 1987, p.11-3). Em outras palavras, seu projeto busca apreender as leis como elas existem objetivamente na natureza. Em vez de explicar epistemologicamente os fenômenos naturais com um método dialético, é uma investigação ontológica na medida em que desenvolve dialeticamente movimentos e evolução na natureza (ver JORDAN, 1967, p.167).

Notavelmente, a dialética da natureza de Engels está vinculada a uma demanda prática para a realização da "liberdade" por meio da "dominação" e do "controle" da natureza externa. Na verdade, a construção do socialismo como uma sociedade livre significa para Engels se tornar o "senhor legítimo e consciente da natureza": 
As potências objetivas e estranhas que até agora governaram a história passarão a ser controladas pelos próprios seres humanos. Só a partir desse momento os seres humanos farão sua história com plena consciência; só a partir desse momento as causas sociais postas em movimento por eles terão, de modo preponderante e em medida crescente, os efeitos que desejam. É o salto da humanidade do reino da necessidade para o reino da liberdade. (ENGELS, 1987a, p.270).

De acordo com Engels, o salto dos seres humanos para o reino da liberdade não ocorre apenas pela abolição da dominação reificada do capital independentemente da consciência e comportamento humanos, mas também ocorre mediante a completa apropriação da lei da natureza.

Obviamente, Engels não acreditava que o reconhecimento das leis da natureza levaria a uma manipulação arbitrária da natureza. Em Dialética da naturę̧a, ele alertou contra a "vingança" da natureza: "Não vamos, entretanto, nos gabar demais por causa de nossas vitórias humanas sobre a natureza. Para cada uma dessas vitórias, a natureza se vinga de nós” (ENGELS, 1987b, p.460-1).

Engels reconheceu os limites da natureza e observou criticamente o comportamento humano arbitrário em relação à natureza, especialmente a produção capitalista orientada para a maximização do lucro no curto prazo. Se a lei da natureza é ignorada, o domínio sobre a natureza falha e o trabalho trará resultados imprevistos: os humanos deixam de ser um sujeito ativo e trabalhador, mas são obrigados a se comportar passivamente à mercê do poder da natureza.

A ecologia de Engels orbitou em torno da "vingança" da natureza e criticou a visão estreita da maximização de lucro. A passagem sobre a ruptura metabólica no volume 3 de $O$ capital também é modificada por Engels de acordo com este esquema de vingança da natureza. A edição de Engels de $O$ capital passou a enfatizar que a violação das leis naturais da vida traria uma consequência fatal para a civilização humana, enquanto a abordagem metodológica exclusiva da teoria metabólica de Marx, que investiga como a lei do valor dominante no metabolismo social modifica o metabolismo natural e causa uma ruptura irreparável, tornou-se pouco clara. Engels julgou que a expressão original de Marx sobre o complexo entre a determinação da forma econômica e o mundo material era difícil de ser compreendida pelos leitores e mudou a frase para um esquema mais "acessível” de vingança da natureza.

O que está por trás dessa mudança editorial de Engels é o fato de que ele não valorizava a teoria do metabolismo de Liebig. Na verdade, Engels em Dialética da natureza referiu-se ao conceito de Liebig de metabolismo no sentido de criticá-lo como um “diletante” em biologia. (ENGELS, 1987b, p.576). Quanto à origem da vida, Liebig negou a possibilidade da evolução histórica da vida orgânica e aceitou a hipótese de "vida eterna" que foi "importada" para o planeta do espaço universal. Engels argumentou que a vida é o processo do metabolismo que historicamente emergiu e evoluiu da não-vida, e a "proteína" confirma este ponto: "A vida é uma forma de existência dos corpos protéicos, cujo elemento essencial consiste no intercâmbio metabólico contínuo com o ambiente natural fora deles” (ENGELS, 1987b, p.578). Engels viu a origem da vida no processo químico de assimilação e excreção de proteínas e apontou para a possibilidade de criar artificialmente um organismo vivo por meio da criação de proteínas em um laboratório. 
Na década de 1840, Liebig concebeu o processo de absorção, assimilação e excreção da nutrição como "metabolismo" e tentou explicar a atividade vital como um processo químico, embora não pudesse abandonar totalmente as ideias vitalistas (ver WENDLING, 2009, p.81). Engels rejeitou o vitalismo de Liebig que separava a biologia da química e reconheceu os inexplicáveis princípios exclusivos dos seres vivos. De acordo com Engels, existe metabolismo de corpos inorgânicos como um intercâmbio químico com seu ambiente e, uma vez que a "proteína" evoluiu historicamente, o metabolismo passa a existir como vida.

Notavelmente, enquanto o conceito de metabolismo de Engels enfatizou o surgimento histórico da proteína, ele rejeitou o entendimento de Liebig sobre o metabolismo e, portanto, não o aplicou às questões ambientais. Consequentemente, está perdida a função da teoria do metabolismo de analisar a relacionalidade dos seres humanos e da natureza, tanto da perspectiva transistórica quanto histórica, e para revelar a particularidade e as contradições dessa relação sob o modo de produção capitalista. Em vez disso, Engels limitou o escopo teórico do metabolismo ao processo de origem e evolução da vida que ocorreu independentemente dos seres humanos. Para o Anti-Dühring de Engels, o motor da dialética caracterizado pela "negação da negação" é "uma lei que (...) é válida nos reinos animal e vegetal, na geologia, na matemática, na história e na filosofia" (ENGELS, 1987a, p.131). O principal papel do "metabolismo", portanto, não é ecológico, mas uma demonstração de que esta lei penetra em toda a natureza.

Embora Engels tenha parcialmente adotado a visão de Liebig, ele não adotou o conceito da perturbação do metabolismo entre os humanos e a terra em $O$ capital, mas manteve o esquema anterior da "antítese da cidade e do campo" em $A$ ideologia alemã. Ele não foi capaz de reconhecer plenamente que o salto teórico de Marx está documentado em sua análise do processo interdependente entre o metabolismo social e natural. Em outros termos, Engels não conseguia compreender inteiramente o fundamento da crítica de Marx à economia política após a década de 1850, que trata de como o metabolismo entre os humanos e a natureza é modificado e reorganizado por meio da subsunção formal e real do trabalho sob o capital. Este é o ponto em que a diferença de economia política entre Marx e Engels levou à ecologia. Certamente, a "antítese de cidade e campo" pode ser reinterpretada com êxito como o antagonismo entre "centro" e "periferia" para analisar o imperialismo ecológico moderno como uma crítica ecológica do capitalismo. No entanto, isso por si só não deve subestimar a importância do fato de que Marx começou a analisar a perturbação do metabolismo entre os humanos e a terra em $O$ capital.

A análise de Marx começou com o reconhecimento de que em todas as sociedades os seres humanos devem trabalhar sobre a natureza. Em seguida, ele analisou por que e como a alienação e a inversão de sujeito e objeto emerge pela forma particular de trabalho sob o modo de produção capitalista. Assim, não basta criticar a crise ecológica denunciando a produção em massa em prol da maximização do lucro ou proclamando moralmente a necessidade da coexistência do homem com a natureza. Segundo Marx, as questões ecológicas devem ser explicadas a partir da "separação" dos seres humanos da natureza como 
condição objetiva fundamental da produção, e é necessário mostrar como a penetração da lógica reificada do capital altera radicalmente a consciência e o comportamento humano e até perturba o metabolismo universal da natureza. Enquanto a "antítese" e a "combinação" da cidade e do campo permaneceram estáticas e abstratas na Ideologia alemã e no Manifesto do Partido Comunista, o conceito de metabolismo em $O$ capital conseguiu analisar o processo histórico dinâmico do processo de produção e acumulação de capital. Também deixa evidente a necessidade da realização de uma produção sustentável para mudar radicalmente a forma de trabalho, ou seja, a abolição do "trabalho privado" e do "trabalho assalariado". Por outro lado, Engels manteve a perspectiva geral da década de 1840 e rejeitou a teoria do metabolismo de Liebig. Considerando que o metabolismo entre os humanos e a natureza como um elo de crítica da economia política e da ecologia está ausente, sua visão permaneceu como uma ideia estática da "vingança" da natureza. Essa diferença também leva a diferentes visões da futura sociedade socialista.

\section{Dialética de "dominação" e "vingança"}

Marx e Engels consideravam o controle consciente e teleológico das leis da natureza por meio do trabalho como uma atividade unicamente humana, e muitas vezes o caracterizaram como "controle" sobre a natureza. Por exemplo, Engels escreveu em Anti-Dühring: "A liberdade, pois, é o domínio de nós próprios e da natureza exterior, baseado na consciência da necessidade natural” (ENGELS, 1987a, p.106). Essas observações são tomadas pelos críticos como uma prova de "prometeísmo". Uma contraprova é a advertência de Engels contra uma "vingança" da natureza, porque ele acreditava na necessidade de reconhecer corretamente a lei da natureza e aplicá-la adequadamente, sendo esta a única maneira de alcançar o reino da liberdade. No entanto, existem novas críticas. Por exemplo, Jason W. Moore argumenta em Capitalism in the web of life que é um pensamento "estático" acreditar que se a lei da natureza continuar a ser ignorada, a natureza se vingará dos humanos um dia. Em Desenvolvimento desigual, Neil Smith também rejeitou este tipo de "apocalipticismo de esquerda" (ver MOORE, 2015, p.80; SMITH, 2008, p.247)

Em contrapartida, Marx não tratou as perturbações do metabolismo universal da natureza sob o capitalismo como uma vingança da natureza. O capital analisou o problema sob mais dois aspectos. Em primeiro lugar, o capital não aceita tais limites impostos pela natureza. Conforme discutido no volume 2 de $O$ capital, "a escala em que esse capital opera para formar valores e produtos é elástica e variável" (MARX, 1978, p.433). Nos Grundrisse, Marx também apontou que a elasticidade do capital é uma força do capital, que confrontado com as dificuldades de acumulação de capital, progressivamente estabelece "um sistema de utilidade geral" por meio do desenvolvimento de tecnologias e da invenção de novos valores de uso. No entanto, uma vez que o capital não pode levar em conta os aspectos materiais, exceto o trabalho abstrato, sua tentativa de superar os limites naturais não resolve sua própria contradição, mas sim a aprofunda em uma escala maior. Uma investigação sobre essa relação dinâmica entre capital e natureza é o 
tema principal do velho Marx. Enquanto Engels formulou a lei transistórica da natureza como a "ciência" do universo, a pesquisa de Marx abarcou cada vez mais tópicos empíricos em geologia, química agrícola e mineralogia. Ou seja, ele pretendia compreender a surpreendente elasticidade do capital no processo histórico interdependente em que os humanos modificam a natureza e vice-versa.

Em segundo lugar, a descrição de Marx da ruptura do metabolismo evita um tom apocalíptico de vingança da natureza e destaca o fator ativo de resistência. A extensão ilimitada da jornada de trabalho, bem como a transformação do processo de produção em busca da produção da mais-valia, resulta na alienação do trabalho e na doença física e mental, que acaba por exigir a regulação consciente do poder reificado, como o estabelecimento da jornada normal de trabalho e escolas de ensino profissionalizante fundadas pelo Estado. Um caminho semelhante pode ser vislumbrado para a natureza. A ruptura do metabolismo universal da natureza obriga o estabelecimento de uma gestão social mais consciente das atividades produtivas, como Marx enfatizou em $O$ capital:

mas ao mesmo tempo que destrói as condições desse metabolismo, engendradas de modo inteiramente natural-espontâneo, a produção capitalista obriga que ele seja sistematicamente restaurado em sua condição de lei reguladora da produção social e numa forma adequada ao pleno desenvolvimento humano. (MARX, 1976, p.637-8).

Uma vez que a produção capitalista não pode levar em conta completamente as dimensões complexas do metabolismo social e natural, ela destrói a natureza, aniquila as possibilidades de coevolução humana e da natureza e até mesmo ameaça a civilização humana. Tudo o que importa para o capital é se a acumulação pode ser alcançada de alguma forma, portanto não o interessa se a maior parte do planeta se torne em um espaço inadequado para a vida humana e animal.

Assim, em vez de esperar o colapso do capitalismo graças à vingança da natureza, é indispensável para a realização da sociedade futura que os indivíduos que enfrentam a crise ecológica global tomem medidas, tendo em vista o controle consciente e ativo sobre o metabolismo com seu meio ambiente.

No volume 3 de $O$ capital, Marx escreveu notavelmente:

O homem social, os produtores associados, regulem racionalmente esse seu metabolismo com a Natureza, trazendo-o para seu controle comunitário, em vez de serem dominados por ele como se fora por uma força cega; que o façam com o mínimo emprego de forças e sob as condições mais dignas e adequadas à sua natureza humana. Mas este sempre continua a ser um reino da necessidade. Além dele é que começa o desenvolvimento das forças humanas, considerado como um fim em si mesmo, o verdadeiro reino da liberdade, mas que só pode florescer sobre aquele reino da necessidade como sua base. (MARX, 1981, p.959).

Como apresentado acima, Engels defendeu a necessidade de aplicar conscientemente a lei da natureza, e o "reino da liberdade" consiste precisamente neste controle sobre a natureza. No entanto, Marx enfatizou outro ponto. Ele pensava nesta questão como uma condição necessária para que os produtores confrontados com a ruptura do metabolismo se associem uns aos outros e coloquem um "poder cego" sob seu controle consciente. Sem esse controle, a existência humana estaria ameaçada. No entanto, "mas este continua a ser sempre um reino da necessidade". A nova sociedade baseada na associação deve realizar o livre desenvolvimento da individualidade, mas isso ocorre para além da 
liberdade de trabalho. O trabalho é indispensável para a existência humana, mas é apenas uma parte da atividade humana. Se a liberdade de trabalho pode ser realizada com a ajuda das forças produtivas desenvolvidas sob o capitalismo, o tempo livre expandido além da liberdade de trabalho deve realizar o verdadeiro reino da liberdade (ver STANLEY, 2002, p.23). ${ }^{3}$

Para Marx, a liberdade não se limita à regulamentação consciente da lei da natureza por meio das ciências naturais, mas inclui atividades criativas de arte, enriquecimento do amor e da amizade e hobbies, como esportes e leitura de livros. Em contraste, Engels, que se preocupava principalmente com a dialética da natureza, dá importância à liberdade humana com base no reconhecimento da lei transistórica da natureza, e é o controle sobre a natureza que realiza imediatamente o reino da liberdade. Essa perspectiva empobrece o conteúdo do reino da liberdade, de modo que Engels não destacou o que Marx formulou como o pleno desenvolvimento da individualidade no comunismo, mas apresentou a visão hegeliana de liberdade que pode ser realizada seguindo conscientemente a necessidade.

\section{Cadernos e crítica da economia política}

A teoria do metabolismo de Marx também contribui para entender o significado de suas anotações sobre ciências naturais após 1868. Orientações para imaginar a parte não escrita de $O$ capital existem nesses cadernos pouco conhecidos. $\mathrm{Na}$ verdade, os interesses de Marx nas ciências naturais vão além da teoria da renda fundiária. Sua aceitação da ideia de Liebig não pode ser restrita a isso, mas trata da reorganização e contradição da relação entre os humanos e a natureza sob a produção capitalista. Em suma, Marx pretendia compreender como os desequilíbrios no mundo material emergem das modificações desse metabolismo pelo poder reificado do capital.

Nesse contexto, os enxertos de Marx referentes a Carl Fraas, um agrônomo alemão, são de grande importância. Em sua carta a Engels datada de 25 de março de 1868, escreve que encontrou uma "tendência socialista inconsciente" depois de fazer anotações detalhadas (MARX E ENGELS, 1987, p.559). Motivado pela alta avaliação de Marx, Engels mais tarde leu o livro O clima e o mundo vegetal ao longo do tempo de Fraas, que trata das mudanças climáticas em civilizações antigas, como Mesopotâmia, Egito e Grécia, devido ao desmatamento massivo. Existem trechos deste livro no caderno de Engels de 18791880. Embora sejam sucintos, uma vez que foram feitos após a utilização do livro de Fraas como referência para Dialética da natureza, a paráfrase de Engels documenta precisamente que sua visão sobre Fraas foi nitidamente influenciada pela de Marx. Nesse sentido, a relação intelectual entre Marx e Engels nas ciências naturais havia se invertido em relação a 1864.

Em primeiro lugar, na carta acima, Marx valorizou significativamente o lampejo de Fraas de que cultivo - quando procede em crescimento natural e não é conscientemente controlado - deixa desertos para trás (MARX e ENGELS, 1987, p.559); e Engels escreveu a mesma opinião em seu caderno: "O desenvolvimento da agricultura popular deixa um enorme deserto para trás."4 Engels também sintetizou a importância do trabalho de Fraas como uma "prova principal de que a civilização em suas formas convencionais é um processo 
antagônico que esgota o solo, devasta a floresta, torna o solo infértil para seus produtos originais e piora o clima". Como exemplo, Engels observou que na Alemanha e na Itália a temperatura média aumentou de 5 para 6 degraus $\left({ }^{\circ} \mathrm{Re}\right) .{ }^{5}$ Esse entendimento de que a produção inconsciente resulta em "desertos" se reflete na vingança da natureza na Dialética da natureza. Na verdade, Engels argumentou em uma importante passagem com base em Fraas:

As pessoas que, na Mesopotâmia, Grécia, Ásia Menor e em outros lugares, destruíram as florestas para obter terras cultiváveis, nunca sonharam que removendo junto com as florestas os centros coletores e reservatórios de umidade eles estavam lançando a base para o atual estado de abandono desses países. (ENGELS, 1987b, p. 461).

Em segundo lugar, Marx na mesma carta caracterizou Fraas como um "darwinista antes de Darwin” (MARX e ENGELS, 1987, p.558), e Engels também citou uma passagem de Fraas que lembra a "seleção natural" de Darwin: "Como disse, o carvalho também é bastante sensível aos elementos do clima natural (temperatura e umidade), e quando há alguma mudança sutil neles, o carvalho é deixado para trás na competição com as árvores circundantes mais duráveis e menos sensíveis que lutam juntas pelo crescimento natural e autopreservação". Engels leu Fraas para refutar a "crença na estabilidade das espécies de plantas" com base em um argumento darwiniano. ${ }^{6}$ Ele deve ter pensado que seu interesse era idêntico ao de Marx.

No entanto, o interesse de Marx em Fraas não se limitou à vingança da natureza e a um argumento darwinista. No início de 1868, Marx, além da obra de Fraas, leu cuidadosamente Einleitung zur Geschichte der Mark-, Hof-, Dorf-, und Stadtverfassung und der offentlichen Gewalt [Introdução à história do mercado, tribunal, aldeia e constituição da cidade e autoridade pública], de Georg Ludwig von Maurer, em que o historiador do direito alemão se dedicou a análise do sistema germânico de propriedade fundiária. $\mathrm{Na}$ mesma carta a Engels datada de 25 de março de 1868, Marx considerou a mesma "tendência socialista" contida na obra de Maurer (MARX e ENGELS, 1987, p.557). Qual o motivo pelo qual Marx estudou simultaneamente a sociedade germânica que parece não ter nenhuma conexão com as ciências naturais? Uma dica para responder esta questão pode ser encontrada no trabalho de Fraas. Em Crise agrária e seus métodos de cura de 1866, Fraas citou o livro de Maurer e avaliou a sustentabilidade das comunas germânicas:

\footnotetext{
Se a aldeia de Mark não permitisse vendas de madeira, palha, esterco e até mesmo gado (porcos!), exceto entre os membros da aldeia, e também ordenasse que todas as safras colhidas no interior da aldeia, e até mesmo o vinho, fossem consumidos dentro da aldeia (dessa prática vários direitos banais [Bannrecht] surgiriam), seriam retidos os meios para a manutenção das forças da terra e, além disso, o uso de nutrientes adicionais de florestas e pastagens e mesmo o uso de prados adubados por rios serviriam para aumentar o poder [do solo] em todos os lugares (FRAAS,1866, p. 210).
}

Frass não afirmou que todas as sociedades pré-capitalistas ignoraram a lei da natureza e deixaram desertos para trás. Em vez disso, na sociedade germânica a produtividade do solo aumentou sob a produção sustentável. Em contraste com as sociedades grega e romana, onde a produção de mercadorias de certo modo existia e o vínculo comunal foi de alguma maneira dissolvido, as comunas germânicas 
impuseram um controle comunal sobre o uso da terra, o que possibilitou o cultivo sustentável. Lendo o livro de Fraas, Marx estava interessado na análise de Maurer para encontrar a "tendência socialista", de modo que ele prestou mais atenção ao metabolismo entre os humanos e a natureza nas sociedades précapitalistas.

Em contraponto a vingança da natureza devido a ignorância sobre lei da natureza nas sociedades pré-capitalistas, Marx reconheceu que o metabolismo sustentável entre os humanos e a natureza na produção comunal funcionou como a fonte de "vitalidade". Em rascunhos de carta a Vera Zasulich, Marx, referindo-se novamente a Maurer, defendeu a possibilidade de a Rússia seguir um caminho socialista baseado em reminiscências da vitalidade de comunas arcaicas sem seguir o desenvolvimento capitalista ocidental (MARX; ENGELS, 1989, p.350-366). Essa vitalidade vem precisamente do poder das comunas agrárias sustentáveis. O metabolismo ali era mediado por uma forma totalmente diferente daquele referente ao capitalismo - mesmo que isso fosse realizado de maneira bastante inconsciente pela tradição e costumes, e não pelo reconhecimento da lei da natureza - e sua sustentabilidade poderia fornecer uma base material para resistência contra a lógica do capital. À medida que Fraas e Maurer se concentravam nessa vitalidade, Marx encontrou uma tendência socialista em suas obras. Aqui reside seu interesse prático em Fraas.

Além disso, os cadernos de Marx de 1878 que contêm trechos geológicos de John Yeats e Joseph Beete Jukes são notáveis no que tange a expansão de sua teoria do metabolismo. Esses longos trechos tratam de vários tópicos, e seu significado não pode ser reduzido à ecologia. No entanto, Marx estudou geologia por causa da economia política. Por exemplo, Marx observou que "grande quantia de dinheiro é desperdiçada apenas na mineração de carvão devido à ignorância" e registra o comentário de Jukes sobre "grande importância prática" da geologia no Manual do estudante de geologia, que é:

um dos pontos principais nas aplicações práticas da geologia nas ilhas britânicas [tanto com o propósito de proteger contra] um desperdício de dinheiro em empreendimentos precipitados, bem como [para] direcioná-lo para onde a empresa [possa ter uma] chance de ser bem-sucedida. ${ }^{7}$

Acrescido a isto, Marx atentou-se à descrição de Jukes sobre como o progresso na geologia melhora os métodos de descoberta e mineração de matérias-primas e materiais auxiliares como carvão e ferro, aumenta a produtividade e como as melhorias no transporte influenciam a relação entre a indústria e a agricultura (bem como indústria extrativa).

Marx também prestou atenção em como o estrato geológico, cuja condição natural não pode ser modificada pelos seres humanos, influencia o desenvolvimento social: "A Inglaterra é dividida em duas partes totalmente diferentes, nas quais a forma e o aspecto do solo, a condição e o empregabilidade das pessoas, [foram] igualmente contrastados um com o outro". A saber, a parte a noroeste desta vida é "principalmente solo paleozóico, muitas vezes selvagem, árido e montanhoso, mas em muitos lugares repletos de riqueza mineral." A parte a sudeste consiste em "solo secundário e terciário, e geralmente macio e suave no contorno, com pouca ou nenhuma riqueza sob o solo." Como resultado, as "populações 
de mineração e manufatura" podem ser encontradas no primeiro distrito, e os "trabalhadores do último" são principalmente "agrícolas". ${ }^{8}$ No volume 1 de $O$ capital, Marx preconizou uma "síntese nova e mais elevada, uma união da agricultura e da indústria" além de sua antítese (MARX, 1976, p.637). No entanto, as características geológicas imutáveis que Jukes apontou devem ser tratadas com muito mais cuidado neste projeto. $\mathrm{Na}$ verdade, Marx destacou essas passagens em seus cadernos para retornar posteriormente.

Em relação a Fraas e Darwin, Jukes também discutiu como o clima e a precipitação afetam a formação geológica, bem como a flora e a fauna. Na seção intitulada "Paleontologia", Jukes, referindo-se diretamente a Darwin, apontou para grandes mudanças climáticas ao longo do tempo e argumentou que "alternância de climas envolve destruição de espécies". Nesse sentido, Marx também destacou a observação de Jukes de que "a extinção de espécies ainda prossegue (o próprio homem é o exterminador mais ativo)."10 Marx estudou as mudanças climáticas de uma perspectiva geológica de longo prazo e seu impacto sobre o meio ambiente, concedendo atenção especial aos impactos humanos, como Fraas o fez. Uma observação semelhante sobre as mudanças climáticas na América do Norte pode ser encontrada em seu excerto de História natural das matérias-primas do comércio de Yeats: "As enormes clareiras, por outro lado, já modificaram sensivelmente o clima"11. Aqui, o interesse de Marx em Darwin e Fraas não se limita aos tópicos enciclopédicos de Engels, como a origem da vida, seleção natural e evolução, mas as formas mais concretas de interação metabólica humana com a natureza.

\section{Conclusão}

Apesar de seus esforços, Marx não foi capaz de integrar totalmente suas novas descobertas em $O$ capital. No entanto, é possível observar diferenças fundamentais entre Marx e Engels. O foco de Engels foi o reconhecimento enciclopédico da lei da natureza com o auxílio das ciências naturais para realizar o reino da liberdade. Enquanto o método materialista de Marx investiga a inevitabilidade da inversão de sujeito / objeto e essência / aparência sob certas relações sociais, o materialismo de Engels, fundado no dualismo de consciência e matéria, defendia a primazia ontológica desta última. É caracterizado por um esquema filosófico e transistórico, e por isso ele acabou rejeitando o conceito de metabolismo de Liebig e basicamente sentiu-se contemplado com a "antítese de cidade e campo" conceituada na década de 1840 .

Em contraste, Marx depois de $A$ ideologia alemã não estava interessado em tais questões filosóficas. Ao enriquecer o conceito de metabolismo ele pretendia compreender a transformação física e social da relação entre os humanos e a natureza a partir da perspectiva histórica, econômica e científica. Especialmente, o desenvolvimento da tecnologia que sob o sistema industrial moderno reorganiza toda a interação metabólica entre a sociedade e a natureza em uma escala sem precedentes. Na década de 1860, Marx reconheceu a potencialidade destrutiva da aplicação tecnológica moderna das ciências naturais como "forças produtivas do capital" e advertiu contra a produção insustentável do capitalismo.

Infelizmente, devido à diferença de interesse teórico, os cadernos de Marx foram totalmente negligenciados por Engels e outros marxistas. Depois de 150 anos desde a publicação do volume 1 de $O$ 
capital, é necessário examinar esses cadernos esquecidos para redescobrir um escopo surpreendente da crítica de Marx à economia política.

\section{Referências:}

BURKETT, Paul. Marxism and ecological economics: toward a red and green political economy. Leiden: Brill, 2006.

CARVER, Terrell. Marx \& Engels: the intellectual relationship. Brighton: Wheatsheaf, 1983.

CLARK, Brett; YORK, Richard. Rifts and shifts. Monthly Review, v.60, n.6, p.13-24, 2008.

ENGELS, Friedrich. Anti-Dühring. In: Marx and Engels collected works, vol. 25. Moscow: Progress Publishers, [1878] 1987a.

ENGELS, Friedrich. Dialectics of nature. In: Marx and Engels collected works, vol. 25. Moscow: Progress Publishers, [1878] 1987b.

ENGELS, Friedrich. The housing question. In: Marx and Engels collected works, vol. 23. Moscow: Progress Publishers, [1872-73] 1988.

FOSTER, John Bellamy. Marx's ecology: materialism and nature. New York: Monthly Review Press, 2000.

FOSTER, John Bellamy. Marx and the rift in the universal metabolism of nature. Monthly Review, v.65, n.7, p.1-19, 2013.

FOSTER, John Bellamy; YORK, Richard; CLARK, Brett. The ecological rift: capitalism's war on the Earth. New York: Monthly Review Press, 2011.

FOSTER, John Bellamy; BURKETT, Paul. Marx and the Earth: an anti-critique. Leiden: Brill, 2016.

FRAAS, Carl. Ackerbaukrisen und ihre Heilmittel. Leipzig: Brockhaus, 1866.

JORDAN, Zbigniew A. The evolution of dialectical materialism. London: Macmillan, 1967.

LUKÁCS, Georg. History and class consciousness. London: Merlin Press, 1971.

MARX, Karl. Grundrisse. London: Penguin Books, 1973.

MARX, Karl. Capital, vol.1. London: Penguin Books, 1976.

MARX, Karl. Capital, vol.2. London: Penguin Books, 1978.

MARX, Karl. Capital, vol.3. London: Penguin Books, 1981.

MARX, Karl. Das kapital (Ökonomische manuskript 1863-1865). Drittes Buch. In: Marx Engels Gesamtausgabe (MEGA²), vol. II/4.2. Berlin: Dietz, [1863-65] 1992.

MARX, Karl; ENGELS, Frederich. Manifesto of the Communist Party. In: Marx Engels collected works, vol. 6. London: Lawrence \& Wishart, 1976. 
MARX, Karl; Engels, Friedrich. Letters 1860-64. In: Marx and Engels collected works, vol. 41. Moscow: Progress Publishers, 1985.

MARX, Karl; ENGELS, Friedrich. Letters 1864-68. In: Marx and Engels collected works, vol. 42. Moscow: Progress Publishers, 1987.

MARX, Karl; ENGELS, Frederich. Preface to the second russian edition of the Manifesto of the Communist Party. In: Marx and Engels collected works, vol.24. New York: International Publishers, 1989.

MARX, Karl; ENGELS, Friedrich. Letters 1880-83. In: Marx and Engels collected works, vol. 46. London: Lawrence \& Wishart, 1992.

MOORE, Jason W. Capitalism in the web of life. London: Verso, 2015.

SMITH, Neil. Uneven development. Athens: The University of Georgia Press, 2008.

STANLEY, John L. Mainlining Marx. Piscataway: Transaction, 2002.

WENDLING, Amy E. Karl Marx on technology and alienation. New York: Palgrave, 2009.

ŽIŽEK, Slavoj. Ecology. In: TAYLOR, Astra (ed.). Examined life: excursions with contemporary thinkers. New York: The New Press, 2009. p.155-83.

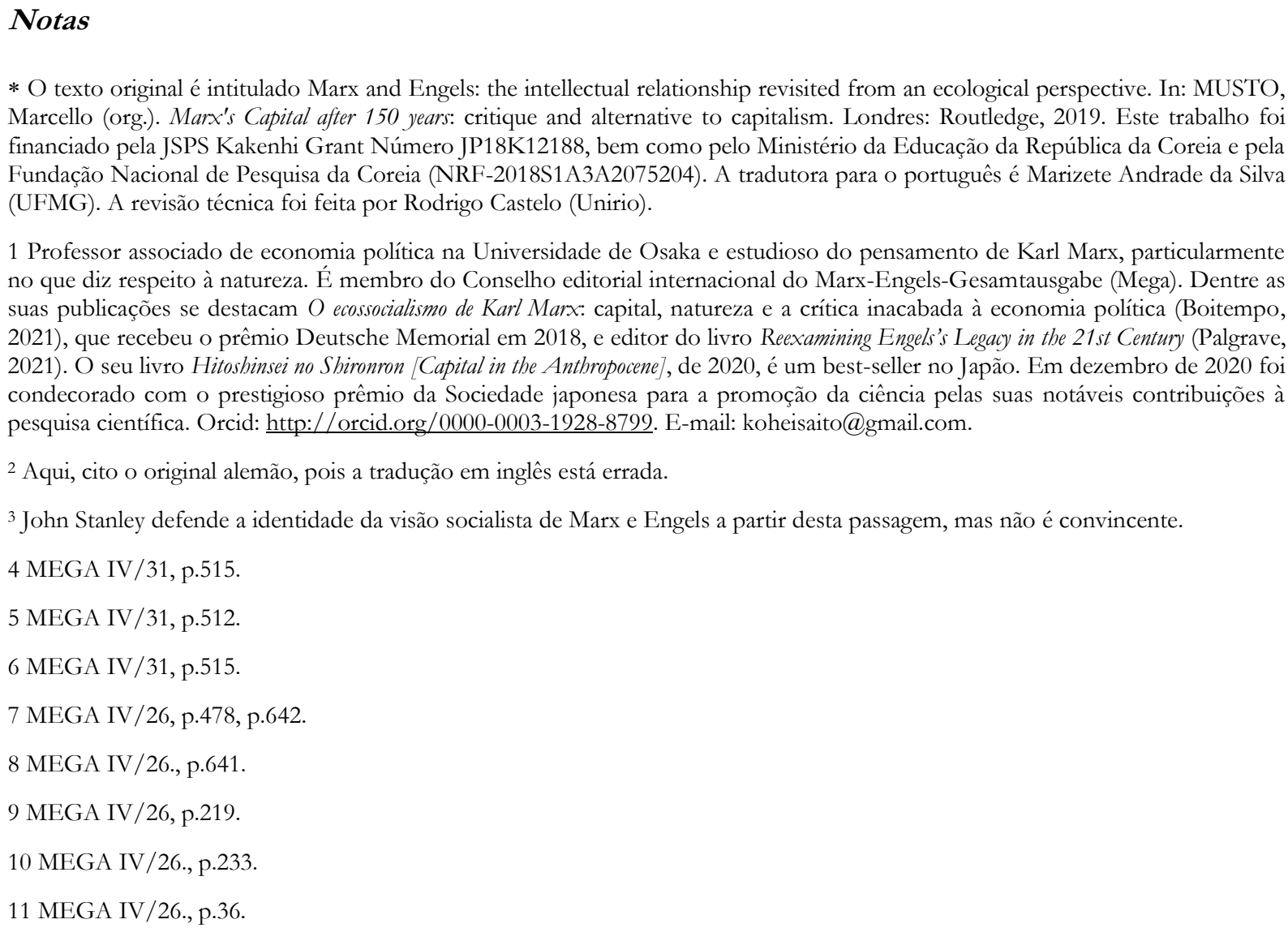

* O texto original é intitulado Marx and Engels: the intellectual relationship revisited from an ecological perspective. In: MUSTO, Marcello (org.). Marx's Capital after 150 years: critique and alternative to capitalism. Londres: Routledge, 2019. Este trabalho foi financiado pela JSPS Kakenhi Grant Número JP18K12188, bem como pelo Ministério da Educação da República da Coreia e pela Fundação Nacional de Pesquisa da Coreia (NRF-2018S1A3A2075204). A tradutora para o português é Marizete Andrade da Silva (UFMG). A revisão técnica foi feita por Rodrigo Castelo (Unirio).

1 Professor associado de economia política na Universidade de Osaka e estudioso do pensamento de Karl Marx, particularmente no que diz respeito à natureza. É membro do Conselho editorial internacional do Marx-Engels-Gesamtausgabe (Mega). Dentre as suas publicações se destacam $O$ ecossocialismo de Karl Marx: capital, natureza e a crítica inacabada à economia política (Boitempo, 2021), que recebeu o prêmio Deutsche Memorial em 2018, e editor do livro Reexamining Engels's Legacy in the 21st Century (Palgrave, 2021). O seu livro Hitoshinsei no Shironron [Capital in the Anthropocene], de 2020, é um best-seller no Japão. Em dezembro de 2020 foi condecorado com o prestigioso prêmio da Sociedade japonesa para a promoção da ciência pelas suas notáveis contribuições à pesquisa científica. Orcid: http://orcid.org/0000-0003-1928-8799. E-mail: koheisaito@gmail.com.

2 Aqui, cito o original alemão, pois a tradução em inglês está errada.

3 John Stanley defende a identidade da visão socialista de Marx e Engels a partir desta passagem, mas não é convincente.

4 MEGA IV/31, p.515.

5 MEGA IV/31, p. 512.

6 MEGA IV/31, p.515.

7 MEGA IV/26, p.478, p.642.

8 MEGA IV/26., p.641.

9 MEGA IV/26, p.219.

10 MEGA IV/26., p.233.

11 MEGA IV/26., p.36. 
Recebido: 22 de julho de 2021

Aprovado: 23 de agosto de 2021 